NBSIR 77-1305

\title{
Provisional Flat Plate Solar Collector Testing Procedures
}

Center for Building Technology Institute for Applied Technology National Bureau of Standards

Washington, D.C. 20234

September 1977

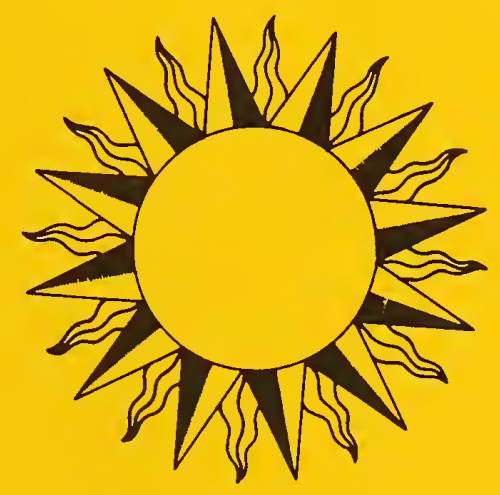

Prepared for

Energy Research and Development Administration Division of Solar Energy

Washington, D.C. 20545 

NBSIR 77-1305

PROVISIONAL FLAT PLATE SOLAR COLLECTOR TESTING PROCEDURES

Center for Building Technology Institute for Applied Technology National Bureau of Standards

Washington, D.C. 20234

September 1977

Prepared for

Energy Research and Development Administration

Division of Solar Energy

Washington, D.C. 20545

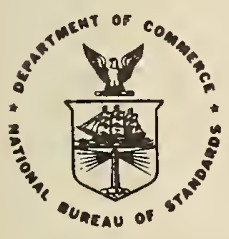

U.S. DEPARTMENT OF COMMERCE, Juanita M. Kreps, Secretary

Dr. Sidney Harman, Under Secretary

Jordan J. Baruch, Assistant Secretary for Science and Technology

NATIONAL BUREAU OF STANDARDS, Ernest Ambler, Acting Director 



\section{ACKNOWLEDGMENTS}

This document was prepared by the Solar Energy Program Team of the National Bureau of Standards, Center for Building Technology, Washington, DC, with the assistance of the Solar Energy Systems Division of Wyle Laboratories, Huntsville, Alabama. Contributors include:

Wyle Laboratories:

David R. Reese

Howard H. Yen

Joe H. Johnson

Robert E. Losey

Wayne L. Swanson

Rick E. Pitman

Janet M. Kennedy
National Bureau of Standards:

David Waksman

Elmer R. Streed

Thomas W. Reichard

Edgar V. Leyendecker

Louis E. Cattaneo

Larry $W$. Masters

William D. Walton 
In view of the present accepted practice in this country for building technology, common U.S. units of measurement have been used throughout this document. In recognition of the position of the United States as a signatory to the General Conference of Weights and Measures, which gave official status to the metric SI system of units in 1960, assistance is given to the reader interested in making use of the coherent system of SI units by giving conversion factors applicable to U.S. units used in this document.

LENGTH

1 in. $=0.0254$ meter (exactly)

$1 \mathrm{ft}=0.3048$ meter (exactly)

AREA
1 in $^{2}=6.45 \times 10^{-4}$ meter $^{2}$
$1 \mathrm{ft}^{2}=0.09290$ meter $^{2}$

VOLUME

1 in $^{3}=1.639 \times 10^{-5}$ meter $^{3}$
1 gal. (U.S. liquid) $=3.785 \times 10^{-3}$ meter $^{3}$

MASS

1 ounce-mass (avoirdupois) $=2.835 \times 10^{-2} \mathrm{kilogram}$

1 pound-mass (avoirdupois) $=0.4536 \mathrm{kilogram}$

PRESSURE OR STRESS (Force/Area)

1 inch of mercury $\left(60^{\circ} \mathrm{F}\right)=3.377 \times 10^{3}$ pascal

1 pound-force/inch ${ }^{2}$ (psi) $=6.895 \times 10^{3}$ pascal

1 pound-force/foot ${ }^{2}(\operatorname{psf})=9.930 \times 10^{5}$ pascal

ENERGY

1 foot-pound-force (ft-lbf) $=1.356$ joule

$1 \mathrm{BTU}$ (International Table) $=1.055 \times 10^{3}$ joule

POWER

1 Watt $=1 \times 10^{7} \mathrm{erg} / \mathrm{second}$

$1 \mathrm{BTU} / \mathrm{hr}=0.2931$ Watt

TEMPERATURE

$t^{\circ} \mathrm{C}=5 / 9\left(t^{\circ} \mathrm{F}-32\right)$

HEAT

$1 \mathrm{BTU} \cdot \mathrm{in} \cdot / \mathrm{hr} \cdot \mathrm{ft}{ }^{2} \cdot{ }^{\circ} \mathrm{F}=1.442 \times 10^{-1} \mathrm{~W} / \mathrm{m} \cdot \mathrm{K}$

(thermal conductivity)

$1 \mathrm{BTU} / \mathrm{lbm} \cdot{ }^{\circ} \mathrm{F}=4.187 \times 10^{3} \mathrm{~J} / \mathrm{kg} \cdot \mathrm{K}$ (specific heat)

1 langley $=4.184 \times 10^{4} \mathrm{~J} / \mathrm{m}^{2}=1 \mathrm{cal} / \mathrm{cm}^{2}=3.69 \mathrm{BTU} / \mathrm{ft}^{2}$ 
1.0 INTRODUCTION 1

2.0 GENERAL 3

2.1 Purpose 3

2.2 Scope 3

2.3 Test and Evaluation Methods 3

2.4 Evaluation Criteria 3

3.0 SELECTION AND CHARACTERIZATION OF TEST SPECIMENS

3.1 Criteria

3.2 Identification

3.3 Materials 5

3.4 Specifications 5

3.5 Drawings/Manuals 6

$\begin{array}{lll}4.0 & \text { RECEIVING INSPECTION } & 7\end{array}$

4.1 Damage Inspection 7

4.2 Documentation Compliance Inspection 7

4.3 Specimen Rejection 7

$\begin{array}{llr}5.0 & \text { SUGGESTED SEQUENCE OF TESTS } & 8\end{array}$

6.0 DOCUMENTATION REQUIREMENTS 9

6.1 General 9

6.2 Instrumentation Calibration Records 9

6.3 Test Data 9

6.4 Final Report 10

$\begin{array}{lll}7.0 & \text { TEST METHODS } & 11\end{array}$

7.1 Thermal Performance Test 11

7.2 No-Flow 30-Day Degradation 12

7.3 Thermal Shock/Water Spray Test 15

7.4 Thermal Shock/Cold Fill 16

$\begin{array}{lll}7.5 & \text { Rain Test } & 17\end{array}$

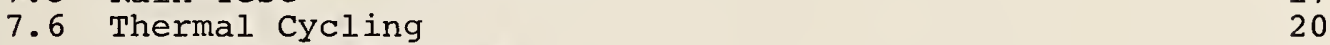

7.7 Positive Live Loads 22

7.8 Negative Live Loads 25

7.9 Longitudinal Loads 30

7.10 Hail Loads 34

7.11 Static Over-Pressure Test 37

7.12 Static Pressure Leakage Test 39

7.13 Fire Tests 41

8.0 REFERENCES $\quad 43$

$\begin{aligned} \text { APPENDIX A } & \text { PROPOSED RATING CRITERIA FOR FLAT PLATE } \\ & \text { SOLAR COLLECTORS }\end{aligned}$

APPENDIX B - CALCULATION OF ALL-DAY SOLAR COLLECTOR EFFICIENCY B-1 

This document was prepared by the National Bureau of Standards with the assistance of Wyle Laboratories. It is intended for use:

1. As the basis of a testing program to be funded by the Energy Research and Development Administration (ERDA). The information obtained during this ERDA program will form a data base that can be used by consumers, code officials, industry representatives and other concerned parties in determining key parameters that wouid affect solar collector performance.

2. As a resource document in the development of collector testing standards by consensus standards organizations such as the American Society for Testing and Materials.

3. As a background document by organizations developing programs for the certification of collector performance.

The test methods contained in this report and the provisional rating criteria presented in Appendix $A$ are intended for use in determining the thermal performance, and to assist in the assessment of the safety and durability/reliability of flat plate solar collectors. These test methods and rating criteria have been selected after the review of over 400 accepted industry standards and are consistent with the intent of the U. S. Department of Housing and Urban Development (HUD) Minimum Property Standards (MPS) [1]* and the Interim Performance Criteria (IPC) prepared by the National Bureau of Standards (NBS) for ERDA and HUD, respectively [2\&3] and can be used as an aid in determining compliance with these documents. These test methods and rating criteria do not, however, represent a consensus of industry and are therefore provisional in nature. It is intended that revisions will be made as more experience is gained and inputs received from appropriate industry representatives, testing laboratories, designers, etc. 
Comments concerning these tests are invited and should be addressed to:

\author{
Manager, Solar Energy Program \\ National Bureau of Standards \\ Building 225, Room A-114 \\ Washington, DC 20234
}


2.0 GENERAL

$2.1 \quad$ Purpose

The purpose of this document is to set forth interim test methods for determining the performance, reliability, durability and safety of flat plate solar collectors. Provisional recommendations for rating criteria utilizing these tests are presented in Appendix $A$.

2.2 Scope

The test methods contained herein apply only to flat plate solar collectors having the following general characteristics:

2.2.1 Multi- or single-glaze cover

2.2.2 Liquid or air single-phase heat transfer fluid

2.2.3 Single point fluid inlet

2.2.4 Single point fluid exit

2.2.5 Separate thermal storage.

2.3 Test and Evaluation Methods

Test methods contained herein address the following specific areas:
a. Thermal Performance
b. Reliability/Durability
c. Safety

2. $4 \quad$ Evaluation Criteria

The evaluation criteria utilized in this document fall into three distinct categories as follows:

2.4.1 Performance Testing - These tests require the use of a test facility specifically designed to evaluate solar collectors in accordance with the requirements set forth in ASHRAE Standard 93-77 [4]. This category includes requirements for no-flow (stagnation) tests and leakage tests. 
2.4.2 Physical Properties and Structural Testing - These tests are used to determine durability, reliability and safety, and require the services of an environmental test facility.

2.4.3 Engineering Review and Analysis - Requires no test facility. Specific requirements regarding the materials used and their properties are contained in the HUD Intermediate MPS (4930.2) [1] and ERDA and HUD IPC $[2,3]$. 
$3.1 \quad$ Criteria

The test specimens should be randomly selected from a normal production run and shall be typical of the product to be sold.

3. 2

\section{Identification}

Each collector submitted for testing shall have permanently affixed thereto the following:

3.2.1 Manufacturer's name and address.

3.2.2 Model name and/or number.

3.2.3 A serial number.

3.3 Materials

Documentation shall be submitted with each collector identifying component materials by commercial designation or composition, including available data to the extent possible concerning the following :

3.3.1 Optical and other properties per Table 2, ASHRAE Standard 93-77 [4].

3.3.2 Insulation and duct liner flame spread per ASTM Standard E-84-76a [9].

$3.4 \quad$ Specifications

A document shall be furnished with each test specimen providing the following information to the extent possible:

3.4.1 Manufacturer's recommended heat transfer fluid.*

3.4.2 Collector operating parameters.*

3.4.2.1 Recommended operating flow rate.*

3.4.2.2 Recommended fill rate.

3.4.2.3 Recommended maximum operation pressure.*

3.4.2.4 Maximum* and minimum permissable no-flow temperature l1mitations.

3.4.2.5 Normal operating temperature range.*

3.4.2.6 Limitations.

Requested in Table 2, ASHRAE 93-77 [4]. 
3.4.3 Mounting and handling instructions.

3.4.4 Structural load limitations.

$3.5 \quad$ Drawings/Manuals

Drawings and/or manuals shall be submitted with each collector in sufficient detail to accurately depict:

3.5.1 Collector dimensions.*

3.5.2 Cover plate dimensions and mounting details.*

3.5.3 Abscrber plate details including:

a. Dimensions

b. Fluid Capacity.

* Requested in Table 2, ASHRAE Standard 93-77 [4]. 
4.0 RECEIVING INSPECTION

4.1 Damage Inspection

Upon receipt of a collector for testing the test laboratory will inspect the shipping container for any visible damage.

4.1.1 Should the container show signs of damage, the Receiving official will document the apparent damage and photograph it as necessary.

4.1.2 Should no apparent damage exist, the Receiving Official will notify the Test Engineer of the specimen's arrival. The Test Engineer will supervise the unpacking. If damage is noted during this process, the Test Engineer will document the damage as in Paragraph 4.1 .1 above.

4.2 Documentation Compliance Inspection

In the event the collector has suffered no apparent shipping damage, the Test Engineer will:

4.2.1 Verify receipt of documentation required in Section 3.0.

4.2.2 Inspect the collector for compliance to drawings and specifications required in section 3.0 .

4.3

Specimen Rejection

Damaged or incomplete test specimens shall be rejected and the supplier notified. 
5.1 Where all tests are conducted, the following sequence is suggested. This sequence requires the use of two collectors for all tests except those concerned with fire testing for ignition from an external source. Times are approximate and could vary considerably depending on location of the test facility.

\begin{tabular}{|c|c|c|c|c|c|}
\hline \multicolumn{3}{|c|}{ Collector \#1 } & \multicolumn{3}{|c|}{ Collector \#2 } \\
\hline Test & Para. & Dàys & Test & Para. & Days \\
\hline Thermal Performance & 7.1 & 5 & Rain & 7.5 & 1 \\
\hline No Flow, 30 Day & 7.2 & 50 & Static Pressure & 7.12 & 1 \\
\hline Shock/Water Spray & $\begin{array}{l}(7.3 \& \\
7.4)\end{array}$ & & Thermal Cycling*** & 7.6 & 10 \\
\hline Cold Fill Tests) & & & Positive, Negative, & $7.7,7.8$, & \\
\hline $\begin{array}{l}\text { Thermal Performance } \\
\text { Check* }\end{array}$ & 7.1 & 5 & $\begin{array}{l}\text { Longitudinal \& Hail } \\
\text { Loads*** }\end{array}$ & $7.9 \& 7.10$ & 5 \\
\hline \multirow{2}{*}{ Fire Test** } & 713 & 7 & Static Over-Pressure & 7.11 & 1 \\
\hline & & & Fire Test & 7.13 & 1 \\
\hline \multicolumn{2}{|l|}{ TOTAL } & 61 & \multicolumn{2}{|l|}{ TOTAL } & 19 \\
\hline
\end{tabular}

5.2 Unless otherwise specified herein all tests shall be conducted with the test specimen mounted in accordance with the manufacturer's recommendations. In the event that the manufacturer provides optional mounting, testing will be performed under the configuration considered the most critical by the test engineer. The rationale for selection shall be included in the test report.

The Thermal Performance Check (ASHRAE Standard 93-77 test after the 30-day cumulative exposure) does not require the 3-day pre-exposure or remeasurement of the incident angle modifier and time constant. The check is conducted to demonstrate the magnitude of changes in the intercept and slope of the efficiency curve. A minimum of three measurements at operating conditions covering the range of 0.1 to $0.4 \mathrm{hr} \cdot{ }^{\circ} \mathrm{F} \cdot \mathrm{ft}^{2} / \mathrm{BTU}$ shall be performed.

** These tests will probably require more than two collectors. The actual number is dependent on the size of the collectors.

*** Includes static pressure leakage testing per 7.12. 
6.1

General

Complete records shall be maintained throughout the test program and shall be verified by signatures of the responsible parties for each phase of the program.

All records pertaining to the test program shall be retained by the test laboratory for a minimum period of two years after the conclusion of testing.

6.2

Instrumentation Calibration Records

The test laboratory shall maintain a documented instrumentation calibration system which assures that each instrument used to record test data is calibrated with standards traceable to NBS or in the case of solar insolation to National Oceanographic and Atmospheric Administration (NOAA). A permanent record must be maintained of all calibrations and a recall system employed which prevents an instrument being used after the expiration of its calibration period.

6.3

Test Data

Data sheets shall be maintained and verified by signature of the Test Engineer and the responsible Technicians. All test data shall be recorded, including:

6.3.1 Date and Time of Test.

6.3.2 Test Specimen Identification.

6.3.3 Model, Serial Number and Accuracy of Each Instrument used to Measure or Record Test Data.

6.3.4 Date of the Last Calibration of Each Instrument.

6.3.5 All data necessary to verify that the test was performed in accordance with the test procedures.

6.3.6 The result of all visual observations made during and after the test.

6.3.7 A complete description of any failures or anomalies that occur during or as the result of testing. 
As a minimum, a report shall be prepared containing the following information concerning each test:

a. Identification of Test

b. Test Specimen Description and Identification

c. Summary of Results

d. Test Conditions

e. Instrumentation and Equipment

f. Test Results

g. A Complete Description of any Failure, including a photograph of the failure if possible

h. A Complete Description of any Deviation to the Test Procedure, including unplanned test halts, or of any anomaly occurring before, during or after tests

i. Tables, Graphs, Charts and Photographs as appropriate

j. All-day efficiency data as computed per Appendix B. 


\subsection{Thermal Performance Test}

Thermal performance testing shall be conducted in accordance with ASHRAE Standard 93-77. A recommended procedure for calculating all-day solar collector efficiency is contained in Appendix B. 


\subsubsection{Purpose}

The purpose of this test is to document potential degradations resulting from prolonged exposure to natural environments. This method involves the exposure of the collector to solar radiation at an actual test site and measuring the change in collector efficiency as a result of the exposure.

\subsubsection{Methodology}

The parameters $F_{R}(\tau \alpha)$ and $F_{R} U_{L}$ shall be determined in accordance with the test procedure described in ASHRAE standard 93-77 both before and after exposing the collector panel assembly to the Exposure Test described below.* Both the before and after collector thermal performance tests (ASHRAE Standard 93-77) shall be performed utilizing the same test facility under similar climatic conditions.

\subsubsection{Test Specimen}

The test specimen shall consist of a complete air or liquid collector panel assembly.

\subsubsection{Pre-Exposure Preparation}

7.2.4.1 Air Collectors shall be sealed and capped with a pressure relief device set to a value of $-0 \%$ to $+10 \%$ of the collector manufacturer's maximum recommended operating pressure. The inlet shall be equipped with a check valve and desiccant to allow the admission of dry air if internal pressures become negative (less than atmospheric).

The Thermal Performance Check (ASHRAE Standard 93-77 test after the 30-day cumulative exposure) does not require the 3-day pre-exposure or remeasurement of the incident angle modifier and time constant. The check is conducted to demonstrate the magnitude of changes in the intercept and slope of the efficiency curve (see Paragraph 19, Reference [4]). A minimum of three measurements of operating conditions $\left[\left(t_{f, i^{-}} t_{a}\right) / I\right]$ covering the range of 0.1 to $0.4 \mathrm{hr} \cdot{ }^{\circ} \mathrm{F} \cdot \mathrm{ft}^{2} / \mathrm{BTU}$ shall be performed. 
7.2.4.2 Liquid Collectors Intended for Use in All systems (with or without draindown) shall be completely filled with distilled water*, following which the inlet shall be sealed and the outlet provided with a pressure relief valve set to a value of $-0 \%$ to $+10 \%$ of the manufacturer's recommended maximum operating pressure.

7.2.4.3 Liquid Collectors Limited to Use in Systems that Draindown when not Operating shall be completely filled with distilled water*, following which the fluid shall be allowed to gravity drain for 15 minutes with the collector mounted at a $45^{\circ}$ tilt angle. The collector inlet shall then be sealed and the outlet provided with a pressure relief valve set to a value of $-0 \%$ to $+10 \%$ of the manufacturer's recommended operating pressure.

7.2.5 Exposure Conditions

Exposure conditions shall consist of 30 days of cumulative exposure to a minimum daily incident solar radiation flux of $1500 \mathrm{BTU} / \mathrm{ft}^{2}$.day as measured in the plane of the collector aperture. The exposure conditions shall include at least one consecutive four-hour period with a minimum flux of $300 \mathrm{BTU} / \mathrm{ft}^{2} \cdot \mathrm{hr} * *$. This exposure must occur after the collectors have boiled dry where applicable. The average ambient temperature shall be $80^{\circ} \mathrm{F}$ or higher during the $300 \mathrm{BTU} / \mathrm{ft}^{2} \cdot \mathrm{hr}$ exposure time. The collector shall be mounted to a rack at a tilt angle such that the incident solar radiation during solar noon is within $\pm 10^{\circ}$ of the normal to the plane of the aperture.

Manufacturer's/designer's recommended fluid shall be used in those instances when they specifically prohibit the use of distilled water.

** Collector orientation changes or supplementary reflectors may be necessary to obtain the $300 \mathrm{BTU} / \mathrm{ft}^{2} \cdot \mathrm{hr}$ insolation level at certain locations. 
7.2.6.1 The exposure conditions including hourly insolation, ambient temperature and wind velocity and daily precipitation shall be recorded to enable determination of the average daily values. Values shall be recorded every 30 minutes during the $300 \mathrm{BTU} / \mathrm{ft}^{2} \cdot \mathrm{hr}$ exposure.

7.2.6.2 A regularly scheduled weekly visual inspection shall be made and a record of changes in the physical construction or appearance of the collector maintained.

7.2.6.3 The results of the pre-test and post-test thermal performance shall be plotted on the same graph for comparison purposes.

Commentary: The purpose of the "no-flow" test is to identify, in a short period of time, potential problems with collector materials or construction. The 30 days do not necessarily have to be consecutive but the test should be performed on a continuous basis until the solar radiation levels have been achieved for 30 cumulative days. It is recognized that other heat transfer fluid materials exist which may be preferred by the manufacturer or designer. If the test is conducted in a manner other than that prescribed, the collector specification shall state the specific conditions used during the test and identify the pertinent limitations regarding collector array installation and operation. The test procedure is based upon draft versions of a test method in preparation by ASTM and will be superceded by a consensus test method as soon as it becomes available. 
7.3 .1

\section{Purpose}

The purpose of this test is to determine the ability of the solar collector to withstand thermal shock caused by heavy rains falling on the heated collectors.

7.3.2 Test Specimen

The test specimen shall consist of a complete air or liquid solar collector panel assembly undergoing 30-day no-flow testing. The inlet, outlet and vent ports not normally exposed to rain shall be sealed. To assure that the collector has reached stagnation temperature, the spray test shall be conducted after one hour of direct sun (minimum $270 \mathrm{BTU} / \mathrm{ft}^{2} \cdot \mathrm{hr}$ ) and oriented within $10^{\circ}$ of the normal to the sun.

7.3.3 Apparatus

The apparatus consists of distilled* water-spray system designed to provide the specified quantity of water in such a manner as to wet the collector uniformly and to wet those areas vulnerable to water penetration during normal exposure to rain. The temperature of the water shall not exceed $86^{\circ} \mathrm{F}$ during the test.

7.3.4 Procedure

STEP 1 - Adjust the water spray to provide $1.8 \mathrm{gal} . / \mathrm{ft}^{2}$ of collector area per hour.

STEP 2 - Direct spray onto collector in such a manner as to wet the surface that would be wet during a normal rain shower. Maintain water spray for five (5) minutes.

STEP 3 - Turn off the water spray and dry exterior surfaces of the collector.

STEP 4 - Inspect collector for evidence of water penetration into the interior.

STEP 5 - Repeat Steps 1, 2, 3 and 4 on three different days.

\subsubsection{Data Requirements}

Document visual evidence of physical damage and water or moisture penetration within the collector housing.

Tap water may be used where mineral deposit buildup does not cause visual obscuration of the cover plate. 
7.4 .1

Purpose

The purpose of this test is to insure the reliability of a solar collector after being subjected to thermal shock induced through filling the hot collector with relatively cool heat transfer fluid during daytime start-up.

\subsubsection{Test Specimen}

The test specimen shall consist of a complete air or liquid collector panel assembly undergoing 30-day no-flow testing. To assure that the collector has reached stagnation temperature, the test shall be conducted after one hour of direct sun (minimum $300 \mathrm{BTU} / \mathrm{ft}^{2} \cdot \mathrm{hr}$ ) and oriented within $10^{\circ}$ of the normal to the sun.*

\subsubsection{Apparatus}

The apparatus consists of a water or air source capable of providing the required quantity of fluid at the manufacturer's specified fill or flow rate. The temperature of the fluid induced into the collector shall not exceed $75^{\circ} \mathrm{F}$.

\subsubsection{Procedure}

STEP 1 - Assure that the collector has reached stagnation temperature.

STEP 2 - Induce fluid flow at the manufacturer's recommended fill or flow rate.**

STEP 3 - Maintain flow for 5 minutes.

STEP 4 - Turn off fluid flow and perform static pressure leakage test in accordance with Paragraph 7.12, "Static Pressure Leakage Test".

STEP 5 - Blow out residual water (liquid collectors). STEP 6 - Reseal inlet and outlet ports.

\subsubsection{Data Requirements}

Document any physical damage or leakage resulting from this test.

\footnotetext{
$\star$

Collectors that have not completely boiled out will be drained prior to conducting this test.

** When the flow rate is not specified, a rate of $1.5 \mathrm{gph} / \mathrm{ft}^{2}$ for liquid-filled collectors and $2 \mathrm{scFM} / \mathrm{ft}^{2}$ for air-filled collectors shall be used.
} 
7.5.1 Purpose

The purpose of this test is to determine the resistance of the solar collector to water penetration when subjected to winddriven rain.

\subsubsection{Test Specimen}

The test specimen shall consist of a complete air or liquid collector panel assembly.

\subsubsection{Apparatus}

The collector shall be mounted in the apparatus illustrated in Figure 1 or any arrangement of equipment capable of performing the test procedure. The water-spray system shall have nozzles spaced to wet those areas vulnerable to water leakage. For additional details on construction and calibration of the waterspray system consult ASTM standard E331 [6]. The test consists of sealing the solar collector into or against one face of a test chamber, supplying air to or exhausting air from the chamber at the rate required to maintain the test pressure difference across the collector, while spraying water onto the face of the collector at the required rate. The application rate of $3.4 \mathrm{gal}$. of water per square foot of effective collector area per hour and an air pressure of $10 \mathrm{lbf} / \mathrm{ft}^{2}$ (1.92 in. head of water) above atmosphere within the chamber is equivalent to $5-1 / 2$ inches of rain per hour accompanied by a $62.5 \mathrm{mph}$ wind [5].

\subsubsection{Procedure}

STEP 1 - Weigh the collector.

STEP 2 - Mount the collector in the test apparatus with the glazing exposed to the water spray and remove any sealing material or construction that is not normally a part of the assembly as installed in or on a building. Inlet, outlet and vent ports not normally exposed to rain shall be vented to outside the test chamber.

STEP 3 - Adjust the water spray to provide a uniformly distributed spray at the rate of $3.4 \mathrm{gph} / \mathrm{ft}^{2}$ over the entire collector top surface. 


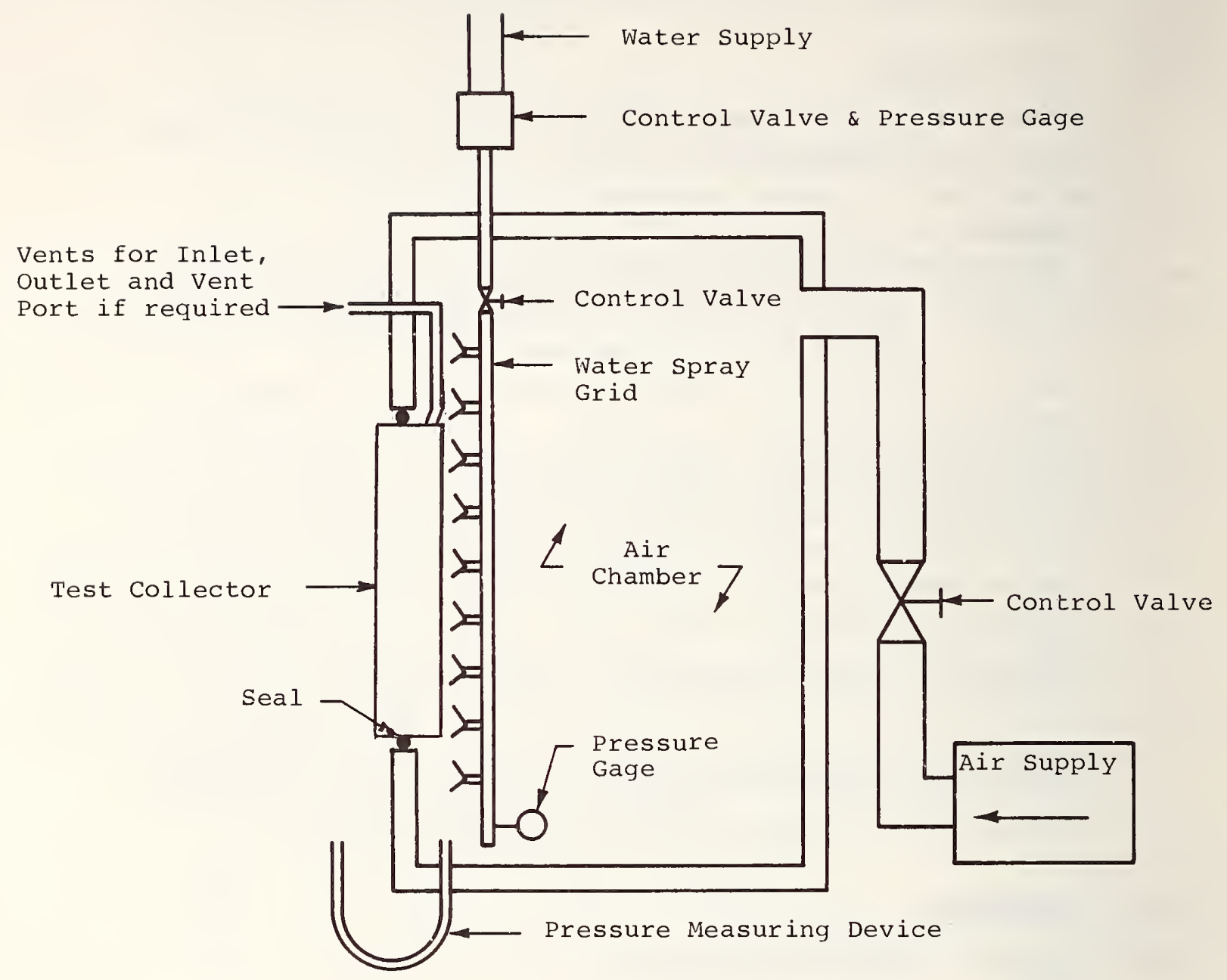

NOTE: For a negative pressure system, the water-spray grid would be located outside the chamber and the air supply would be replaced by an air-exhaust system.

FIGURE 1. APPARATUS FOR RAIN TEST 
STEP 4 - Apply an air-pressure difference of $101 \mathrm{bf} / \mathrm{ft}^{2}$ (1.92 in. head of water).

STEP 5 - Maintain air-pressure difference and water spray for 15 minutes.

STEP 6 - Remove the air-pressure difference and stop the water spray.

STEP 7 - Dry exterior collector surfaces and weigh the collector. Observe and record the points of water penetration into the collector interior.

STEP $8^{*}$ - Mount the collector in the test apparatus to expose the opposite side or the water-spray system may be moved outside the test chamber and a negative pressure applied in the test chamber.

STEP 9 - Repeat Steps 3 through 7 with a water spray and air-pressure difference of one-half the values ( $1.7 \mathrm{gph} / \mathrm{ft}^{2}$ and $\left.51 \mathrm{bf} / \mathrm{ft}^{2}\right)$.

7.5.5 Data Requirements

Document any change in weight or visual evidence of water or moisture penetration resulting from the rain test.

Applies only to collectors that are exposed to wind-driven rain on back surface or edges. 
7.6.1 Purpose

The purpose of this test is to insure the reliability of a solar collector after being subjected to periodic freezing conditions.

\subsubsection{Test Specimen}

The test specimen shall consist of a complete air or liquid collector panel assembly. The initial leakage rate of the specimen shall be determined in accordance with Paragraph 7.12. In addition:

A. Air Collectors shall be sealed and capped with a pressure relief device set to a value of $-0 \%$ to $+10 \%$ of the collector manufacturer's maximum recommended operating pressure. The inlet shall be equipped with a check valve and desiccant to allow the admission of dry air if internal pressures of less than one atmosphere occur.

B. Liquid Collectors Intended for Use in all Systems (with or without Draindown) shall be completely filled with the manufacturer's recommended fluid, following which the inlet shall be sealed and the outlet provided with a pressure relief valve set to a value of within $-0 \%$ to $+10 \%$ of the manufacturer's recommended maximum operating pressure.

C. Liquid Collectors Limited to Use in Systems that Draindown when not Operating shall be completely filled with the collector manufacturer's recommended fluid (usually water), following which the fluid shall be allowed to gravity drain for 15 minutes with the collector mounted at a $45^{\circ}$ tilt angle.

D. A Temperature Sensing Device shall be installed in the collector inlet or outlet as close to the absorber plate as possible, and connected to a direct reading device outside the test chamber.

\subsubsection{Apparatus}

A temperature chamber capable of cycling the enclosed temperature region from ambient to $-25^{\circ} \mathrm{F}$ at a rate of $40^{\circ} \mathrm{F}$ to $60^{\circ} \mathrm{F}$ per hour. 


\subsubsection{Procedure}

STEP 1 - Place the collector in the temperature chamber using standard installation techniques.

STEP 2 - Lower the internal chamber temperature to $-25^{\circ} \mathrm{F}$ at a rate of $40^{\circ} \mathrm{F}$ to $60^{\circ} \mathrm{F}$ per hour and maintain until temperature sensor reaches $-10^{\circ} \mathrm{F}$. Lower test temperatures should be used when specified by the collector manufacturer.

STEP 3 - Raise the internal chamber temperature to ambient $\left(\sim 70^{\circ} \mathrm{F}\right)$ at a rate of $40^{\circ} \mathrm{F}$ to $60^{\circ} \mathrm{F}$ per hour and maintain until absorber plate temperature reaches ambient temperature. STEP 4 - Repeat Steps 2 and 3 for a total of ten (10) cycles. STEP 5 - Static pressure leak test in accordance with Paragraph 7.12 to verify structural integrity.

\subsubsection{Data Requirements}

Document any visual evidence of damage and leakage per Paragraph 7.12 . 
7.7.1 Purpose

The purpose of this test is to determine the ability of a flat plate collector to function satisfactorily after being subjected to uniformly distributed loads resulting from snow and/or positive wind pressure.

Test Specimen

The test specimen shall consist of a complete air or liquid collector unit including mounting brackets or fixtures normally supplied with or specified by the manufacturer of the collector, and the fixtures and fittings required to perform the "Static Pressure Leakage Test" specified in Paragraph 7.12 .

7.7.3 Apparatus

The collector to be tested shall be mounted in the apparatus illustrated in Figure 2. The collector shall be supported on the test bed in accordance with the manufacturer's recommendations. Connect a reaction platform wider and longer than the specimen and parallel to the face to be loaded. The reaction platform shall be supported by use of tie rods. Place an airtight bag (20-mil PVC plastic film or other pliable material) as wide as the specimen and as long as the span, between the specimen and the reaction platform. Apply a load to the specimen by increasing the air pressure in the bag. Measure the pressure with an accuracy of $\pm 1 \%$ by means of a manometer or other pressure measuring device.

\subsubsection{Procedure}

STEP 1 - Mount the collector in the loading apparatus such that the glazing surface is subjected to the applied load.

STEP 2 - Determine the initial leakage rate of the collector in accordance with Paragraph 7.12 .

STEP 3 - Apply a uniform load of 30 psf at the rate of 5 psf per minute.

STEP 4 - Maintain the 30 psf load for a period of ten minutes and then relieve the applied load.

STEP 5 - Determine the leakage rate in accordance with Paragraph 7.12 . 


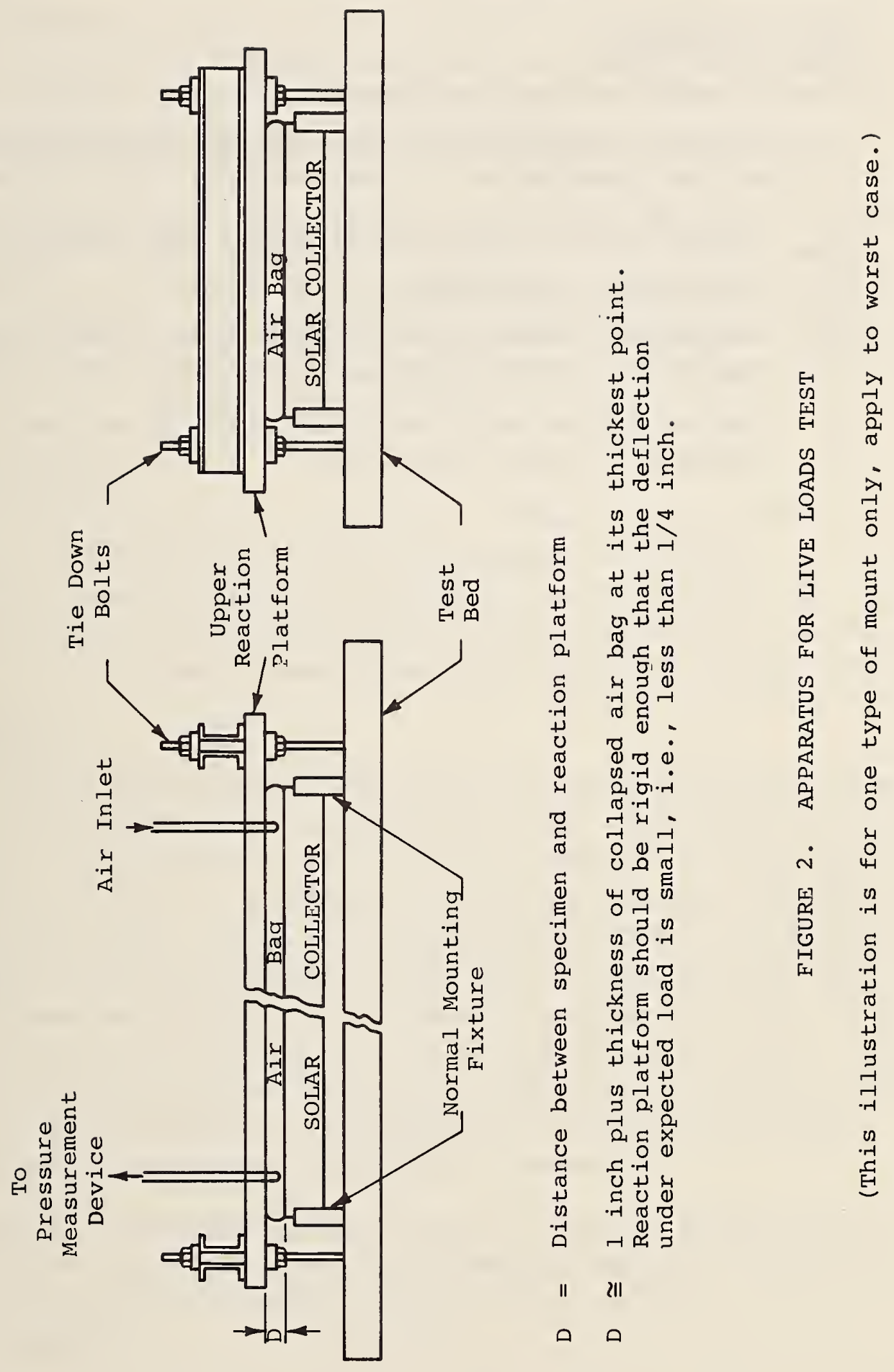


STEP 6 - Repeat Steps 3, 4 and 5 increasing the applied load in increments of 20 psf until some type of physical damage is observed or to a maximum of 150 psf.

7.7 .5

Data Requirements

The following data shall be recorded:

A. Complete description of the collector and method of mounting to the test bed.

B. Leakage rates, initial and at end of each load cycle.

C. The maximum load applied.

D. The physical damage, distortion or other structural problems observed during or following the test.

E. Applied load at which physical damage, distortion or other structural problems occurred. 
7.8 .1

\section{Purpose}

The purpose of this test is to determine the ability of a flat plate collector to function satisfactorily after being subjected to uniformly distributed loads resulting from either of the two following cases. Case 1 applies when the wind has access primarily to the outer surface of the collector which would create a suction on that surface. Case 2 applies when the wind has access to both surfaces of the collector and would create a combination of suction on the outer surface and uplift on the inner surface; i.e., when the collector is intended for installation on open racks or on stand-offs greater than twelve (12) inches from a surface such as a roof*.

7.8.2 Test Specimen

The test specimen shall consist of a complete air or liquid collector unit including mounting brackets or fixtures normally supplied with or specified by the manufacturer of the collector and the fixtures and fittings required to perform the "Static Pressure Leakage Test" specified in Paragraph 7.12.

7.8 .3

\section{Apparatus}

The test specimen shall be mounted to the test bed in accordance with the manufacturer's instructions and as illustrated in either Figure 3 or Figure 4. Collectors with rigid flat glazing materials shall be tested using Method $A$ in the apparatus shown in Figure 3. Collectors which cannot be suction loaded with the equipment for Method A (i.e., corrugated, curved or thin film glazings) shall be tested using Method $B$ in the apparatus shown in Figure 4. The load measuring equipment, load cell, manometer and so forth shall be capable of measuring the applied loads with an accuracy of $2 \%$. An air bag as described in Paragraph 7.7 is placed under the specimen to provide uplift for Case 2 tests.

7.8.3.1 Method A - The apparatus for Method A, Figure 3, consists of a series of vacuum lift cups (glass handling equipment) applied to the glazing and attached to an articulated whiffle tree arrangement.

Wind uplift is generally negligible for small spacings. 


\section{Crane Lift with Ram (Tension)}

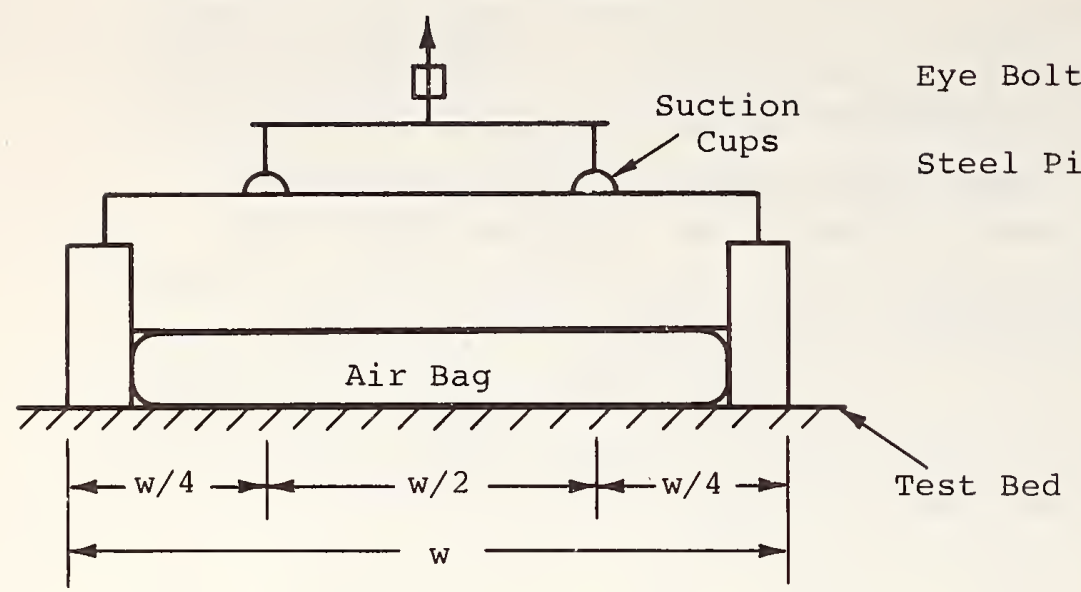

$w=$ Width of Glazing

END VIEW

Crane Life with Ram (Tension)

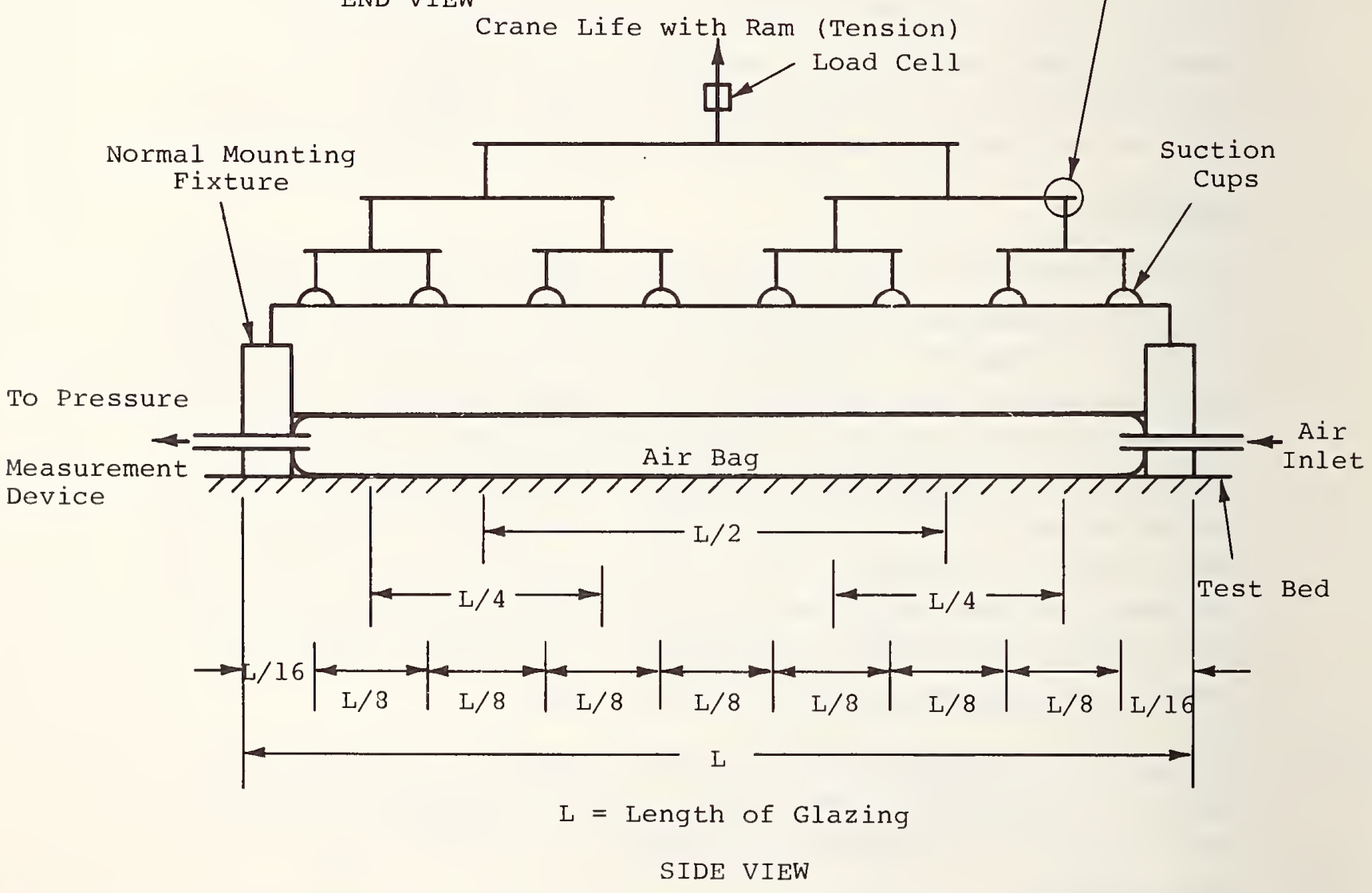

NOTE: The number of suction cups shall be $2^{\mathrm{n}}$ (where $\mathrm{n}$ is an integer).

FIGURE 3. METHOD A - APPARATUS FOR NEGATIVE LIVE LOADS TEST (air bags for Case 2 only) 
7.8.3.2 Method B - For Method B, Figure 4, the apparatus consists of a rigid vacuum chamber with the collector forming one side of the chamber and includes a vacuum device capable of providing the required load.

\section{$7.8 .4 \quad$ Procedure}

The loads applied under these procedures are the sum of the suction and the uplift loads for the Case 2 test and suction load only for the case 1 test. The suction and uplift loads are equal for the Case 2 test.

STEP 1 - Mount the specimen to the test bed such that the glazing surface will be lifted by the applied suction loads. For Case 2 tests, clearance must be provided for installation of the air bag between the test bed and the specimen.

STEP 2 - Determine the initial leakage rate of the collector in accordance with Paragraph 7.12.

STEP 3 - Apply a load of 20 psf at a rate of 10 psf per minute. For Case 2 tests this 20 psf load is applied simultaneously in both suction and uplift for a total of 40 psf.

STEP 4 - Maintain the load for one (1) minute and then gradually remove the load.

STEP 5 - Determine the leakage rate of the collector in accordance with Paragraph 7.12.

STEP 6 - Apply a load of 40 psf at a rate of 10 psf per minute. This is a total of 80 psf for case 2 tests.

STEP 7 - Maintain the load for one (1) minute and then gradually remove the load.

STEP 8 - Repeat Step 5.

STEP 9 - Apply a load of 50 psf at a rate of 10 psf per minute. This is a total of 100 psf for Case 2 tests.

STEP 10 - Repeat Step 7.

STEP 11 - Repeat Step 5. 


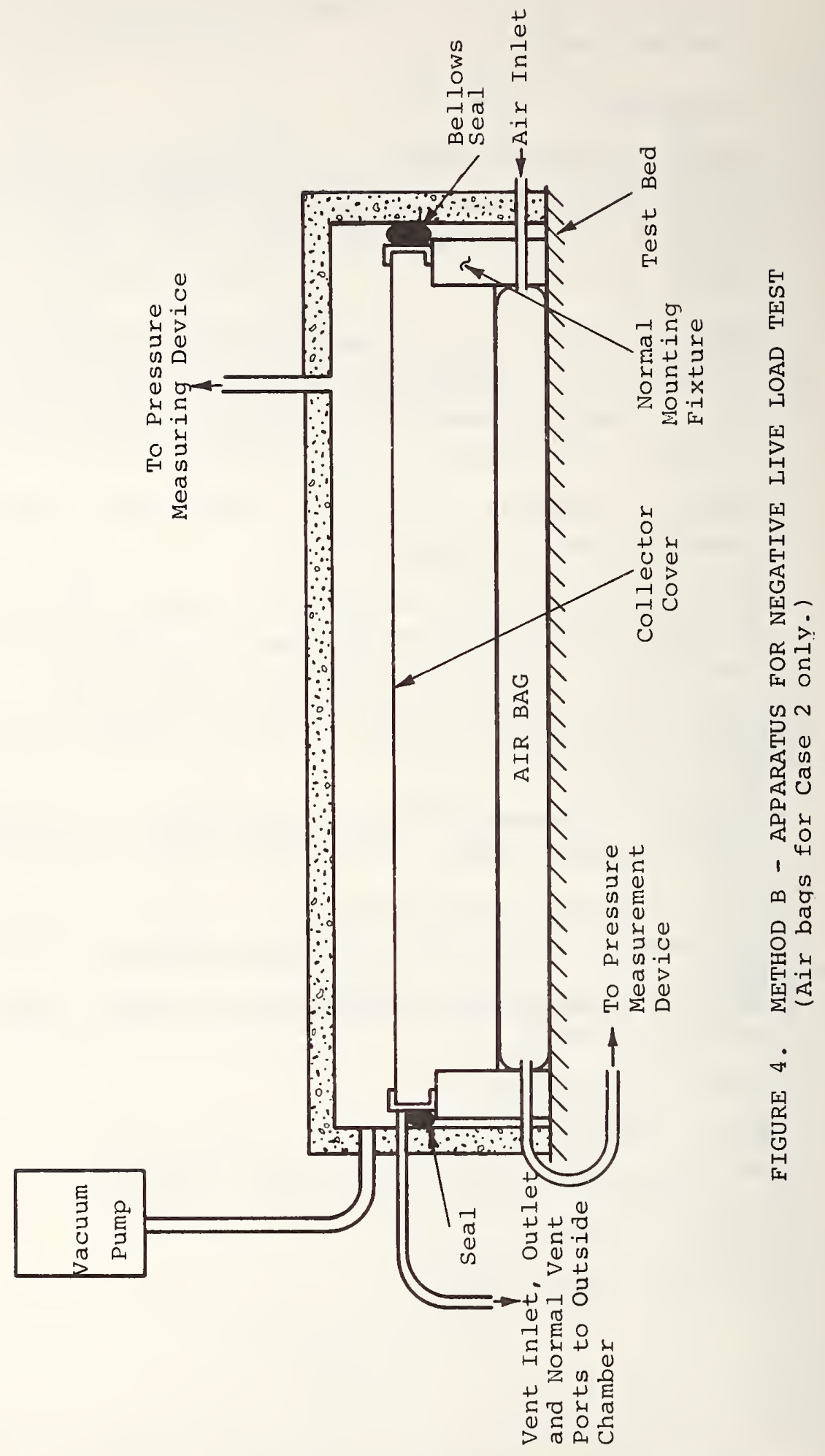


STEP 12 - Continue the cyclic application of the loading to the collector by increasing the applied load in 10 psf increments (total of 20 psf for Case 2 tests) until some type of physical damage is observed or a maximum load of 90 psf is obtained (180 psf for Case 2 tests). The leakage rate shall continue to be performed at the end of each cycle.

7.8.5 Data Requirements

The following data shall be reported:

A. Complete description of collector and method of mounting onto the test bed.

B. The test apparatus used (Method A or B).

C. The type of test performed (Case 1 or 2).

D. The leakage rate (initial and at the end of each load cycle).

E. A description of any physical damage or distortions observed during and after the tests.

F. The applied load at which physical damage, distortion or other structural problems cccurred. 


\subsubsection{Purpose}

The purpose of this test is to determine the ability of the collector and its mountings to withstand cyclic loads in the plane of its longitudinal axis.

\subsubsection{Test Specimen}

The test specimen shall consist of a complete collector panel and any mounting brackets or fixtures normally supplied with or specified by the manufacturer. The specimen shall be mounted in the test apparatus in accordance with the manufacturer's normal mounting instructions.

7.9.3 Apparatus

This test may be performed using either one of the two methods discussed below. When tested by Method $A$, the collector is tested horizontally with the apparatus illustrated in Figure 5 . When tested by Method B, the collector is tested vertically or at an angle with the apparatus illustrated in Figure 6. The loading equipment shall be capable of applying loads with an accuracy of $1 \%$.

\subsubsection{Method A}

The test apparatus shall consist of a hydraulic jack or other equivalent means for maintaining a pre-load and imposing an additional load on the collector. The pre-load force shall be equal to the maximum filled weight of the collector. The imposed additional load shall be equal to $50 \%$ of the maximum filled weight of the collector. The pre-load shall be maintained on the specimen for the duration of the test.

\subsubsection{Method B}

The test apparatus shall consist of weights or other equivalent loading methods that will apply a load parallel to the long axis of the test specimen. Provisions shall be made to remove the load as quickly as possible. 


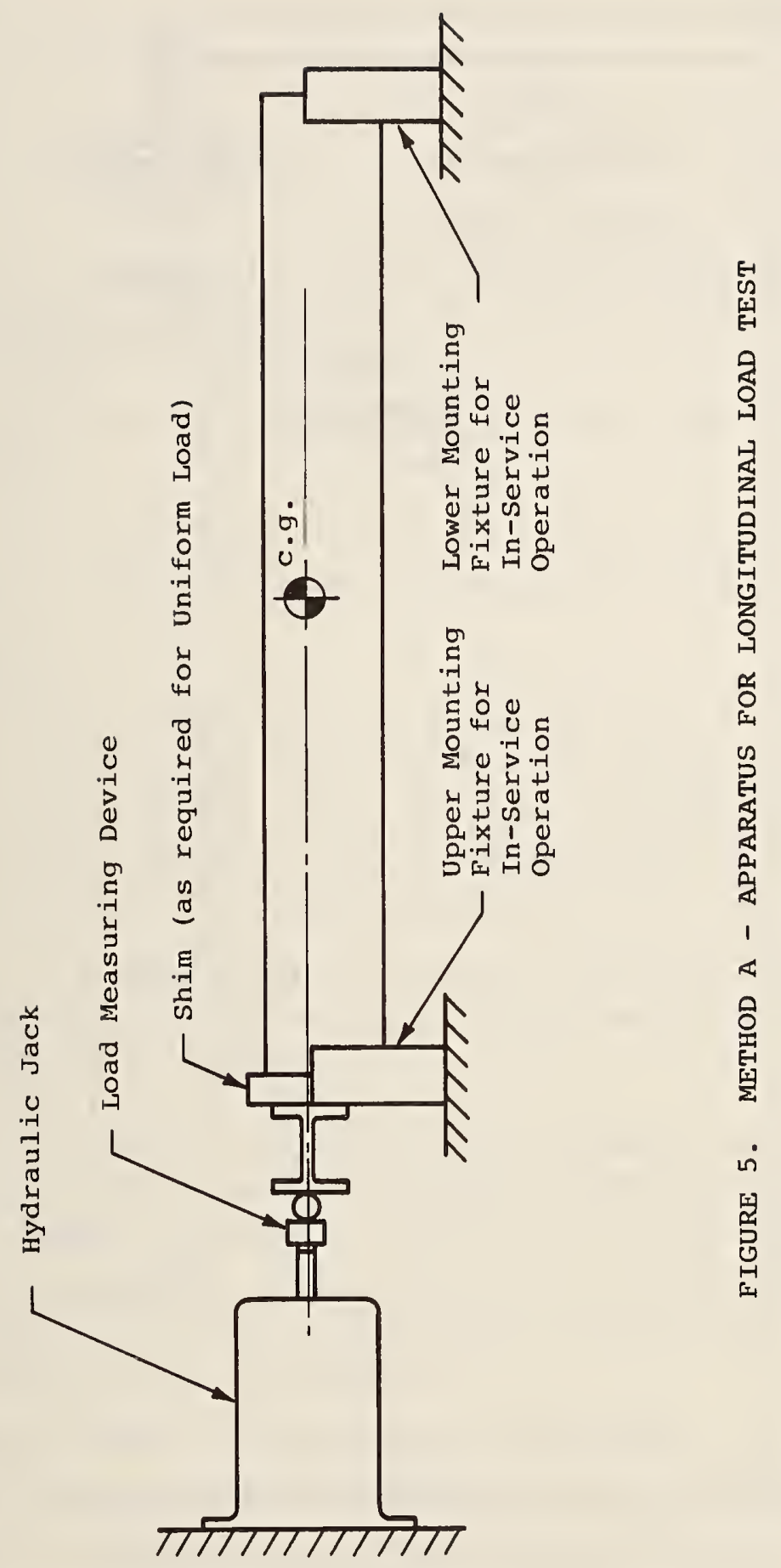




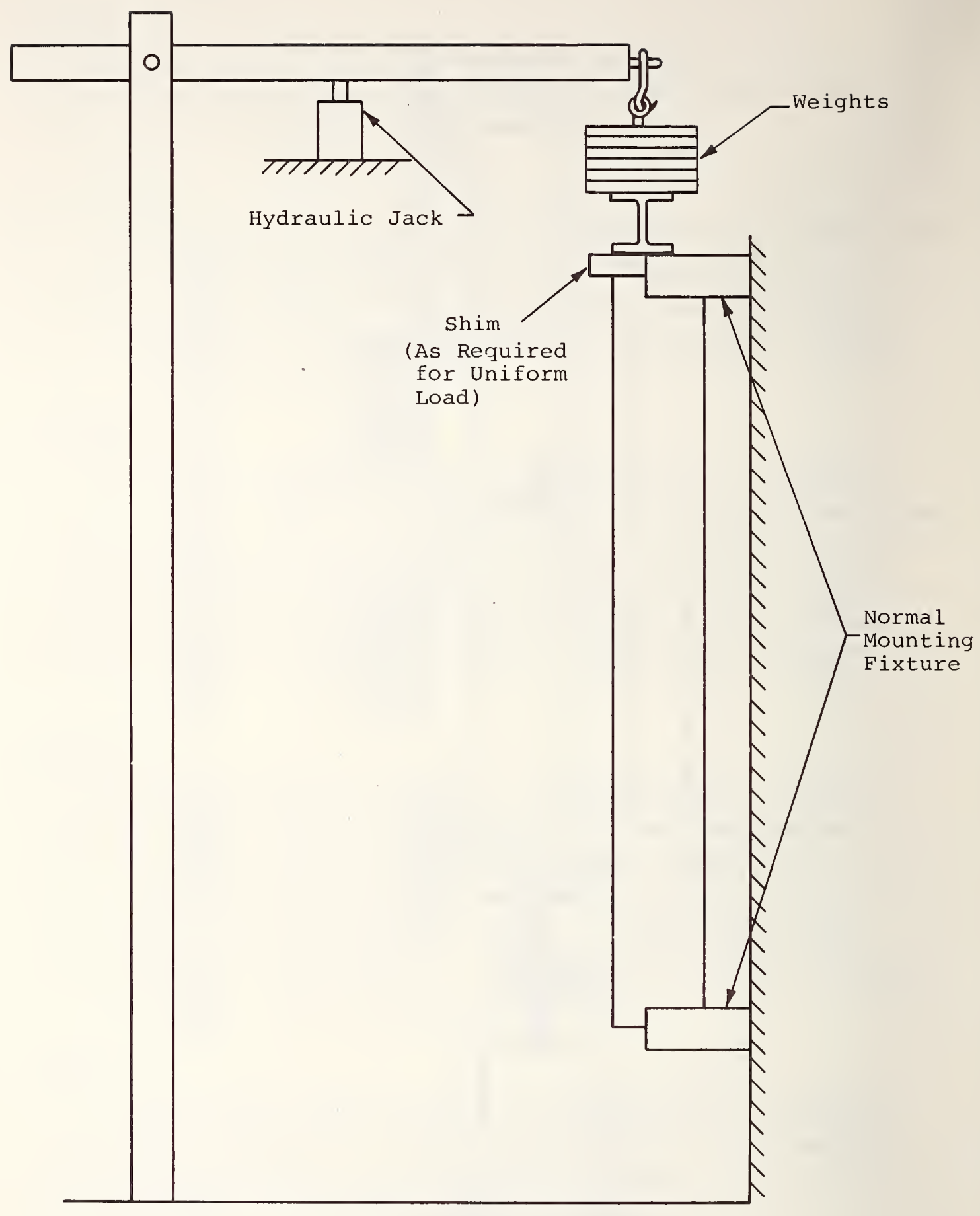

FIGURE 6. METHOD B - APPARATUS FOR LONGITUDINAL LOAD TEST 


\subsubsection{Procedure}

\subsubsection{Method A}

STEP 1 - Mount the collector on the test bed utilizing the manufacturer's normal mounting method.

STEP 2 - Attach the loading device in such a manner that a load will be imposed parallel to the test bed and through the center of gravity of the collector. Apply the pre-load force.

STEP 3 - Increase the load to $150 \%$ of the maximum filled collector weight at a rate faster than $25 \%$ of filled weight per second and hold for two (2) minutes.

STEP 4 - Reduce the load to the pre-load value as quickly as possible.

STEP 5 - Repeat Steps 3 and 4 for a total of fifty (50) cycles. STEP 6 - Inspect collector for structural damage.

\subsubsection{Method B}

STEP 1 - The collector to be tested shall be mounted on a flat, rigid, vertical wall as illustrated in Figure 6 , or on a flat, rigid, inclined wall that represents the normal mounting installation position. Air Collectors shall be sealed and capped. Liquid Collectors shall be completely filled with tap water.

NOTE: Bleeder valves or petcocks should be provided at the highest point in the system to permit venting of all air during the filling operation.

STEP 2 - Attach the loading device or apply weights in such a manner that a load will be imposed parallel to the test bed and through the center of gravity of the collector.

STEP 3 - Apply the load to 50\% of the maximum filled collector weight at a rate faster than $25 \%$ of filled weight per second and hold for two (2) minutes.

STEP 4 - Remove load as quickly as possible.

STEP 5 - Repeat Steps 4 and 5 for a total of fifty (50) cycles. $\underline{\text { STEP } 6}$ - Inspect collector for structural damage.

7.9.5 Data Requirements

Document applied loads and any structural damage or degradation resulting from this test. 
7.10.1 Purpose

The purpose of this test is to determine the ability of the collector cover plate (glazing) to withstand impact forces from hailstones or similar flying objects.

7.10.2 Test Specimen

The test specimen shall consist of a complete collector panel and any mounting brackets or fixtures normally supplied with or specified by the manufacturer. The specimen shall be supported horizontally on the test bed by the mounting brackets or fixtures supplied with the collector.

\subsubsection{Apparatus}

The apparatus shall consist of two (2) steel balls ( 1 in. diameter and 1-1/2 in. diameter) and the equipment required to hold, aim and drop the steel balls the required distance onto the specified points on the collector glazing. The weights of the balls shall be $0.147 \mathrm{lb} \pm 1 \%$ for the $1 \mathrm{in}$. and $0.500 \mathrm{lb} \pm 1 \%$ for the $1-1 / 2 \mathrm{in}$.

\subsubsection{Procedure}

The test procedure consists of dropping the 1 in. steel ball

9.5 feet, and the 1-1/2 in. steel ball 14.5 feet onto the specified points on the glazing of the horizontal collector.

STEP 1 - Support the collector in a horizontal plane beneath the drop point. The collector shall be supported on a rigid surface by means of normal mounting fixtures.

STEP 2 - The impact point on the specimen shall be at a point six (6) inches from each of the two intersecting edges of the glazing (see Figure 7).

STEP 3 - Apply an impact load by dropping the 1 in. steel ball from 9.5 feet onto the specified point.

STEP 4 - Apply an impact load by dropping the 1-1/2 in. steel ball on the same point from 14.5 feet.

STEP 5 - Repeat Steps 3 and 4 for two (2) additional impact points on the specimen, if undamaged by previous impacts. 


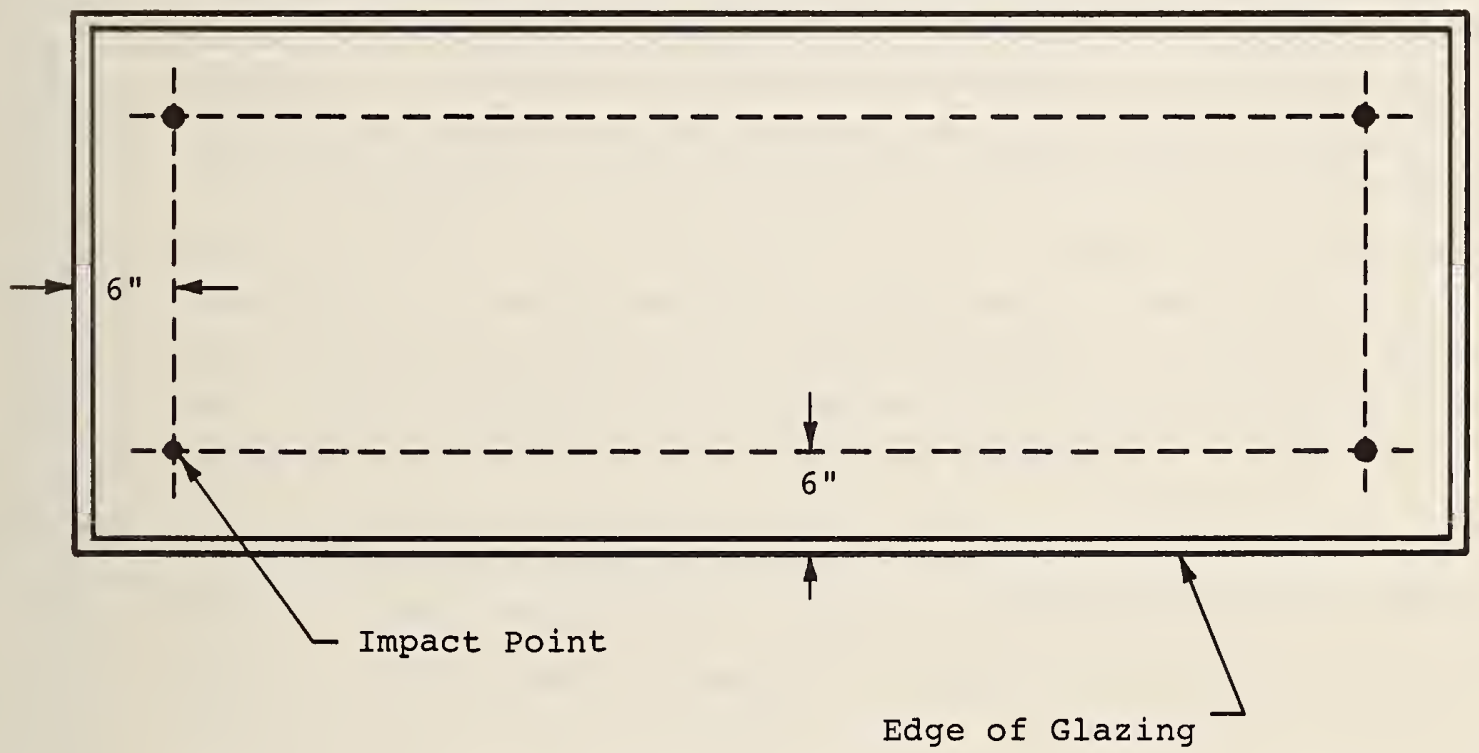

FIGURE 7. POINT OF IMPACT ON GLAZING 
STEP 6 - Measure the depth of indentation and describe the damage including cracking, breaking, fracture, tearing or puncture.

\subsubsection{Data Requirements}

Document any structural damage resulting from this test and the impact load at which it occurred. 


\subsubsection{Purpose}

The purpose of this test is to determine the ability of the collector to withstand excess pressure, resulting from variations in supply source or malfunction of the system.

\subsection{1 .2 Test Specimen}

The test specimen shall consist of a complete solar collector panel assembly. Liquid collectors shall be prefilled with tap water.

\subsubsection{Apparatus}

The apparatus consists of a hydrostatic pressure source or air supply and necessary regulators to maintain the specified static pressure. A pressure tap shall be installed in the collector outlet port which shall be sealed and capped with a pressure relief device set to a value within -0 to $+10 \%$ of the specified test pressure. For air collectors, the pressure tap shall be connected to a water manometer which can be read accurately to 0.05 inch water column or a pressure gauge of equivalent accuracy. For liquid collectors, the pressure tap shall be connected to a pressure gauge which can be read accurately to 0.1 psi.

\subsubsection{Procedure}

STEP 1 - Check the pressure gauge or manometer for zero reading. STEP 2 - Attach the air supply or hydrostatic pressure source to the inlet port of the collector.

STEP 3 - Increase regulated pressure to the level indicated below:

Air Collectors - Two and one-half times the collector manufacturer's maximum recommended operating pressure, but not less than $1-1 / 4$ inch water column. Maintain this pressure for a period of one (1) hour [7].

Liquid Collectors - One and one-half times the collector manufacturer's maximum recommended operating pressure, but not less than 25 psig. Close the inlet valve and hold the pressure for 15 minutes [1].

STEP 4 - Document any pressure drops indicated on the exit pressure gauge and visible liquid leakage. STEP 5 - Decrease the pressure to ambient. 
STEP 6 - Check the pressure gauge or manometer for zero reading.

STEP 7 - Inspect the collector for evidence of structural damage.

7.11.5 Data Requirements

Documentation of applied pressure, structural damage, visible

liquid leakage, evidence of excessive air leakage, and if pressure drop is observed, the rate of pressure drop. 
7.12 .1 Purpose

The purpose of this test is to determine leakage and to indicate damage induced by other tests in this test plan.

7.12.2 Test Specimen

The test specimen shall consist of a complete solar collector panel assembly. Liquid collectors shall be prefilled with tap water.

\subsubsection{Apparatus}

The apparatus consists of hydrostatic pressure source or air supply and necessary regulators to maintain the specified static pressure. A pressure tap shall be installed in the collector outlet port which shall be sealed and capped with a pressure relief device set to a value within -0 to $+10 \%$ of the specified test pressure. For air collectors, the pressure tap shall be connected to a water manometer which can be read accurately to 0.01 inch water column or a pressure gauge of equivalent accuracy. Air collectors shall be tested in accordance with UL Standard 181 [7]. An air meter accurate to within \pm 0.50 cubic feet under the conditions of test shall be placed between the air supply source and test specimen. The meter is to indicate the total volume of air supplied to the sample over the period of the test. For liquid collectors, the pressure tap shall be connected to a pressure gauge which can be read accurately. 0.1 psi.

\section{$7.12 .4 \quad$ Procedure}

STEP 1 - Check the pressure gauge or manometer for zero reading. STEP 2 - Set the pressure regulator to ambient pressure.

STEP 3 - Attach the air supply or hydrostatic pressure source to the inlet port of the collector.

STEP 4 - Increase regulated pressure to not less than:

Air Collectors - One-half inch water column and maintain this pressure for one (1) hour [7].

Liquid Collectors - One and one-half times the collector manufacturer's maximum recommended operating pressure, but not less than 25 psig. Close the inlet valve and hold the pressure for 15 minutes [1]. 
Liquid Collectors - Document any pressure drop indicated on the exit pressure gauge [1].

Air Collectors - Document the volume of air required to maintain the pressure during the period of the test. STEP 6 - Decrease the pressure to ambient. STEP 7 - Check the pressure gauge or manometer for zero reading.

\subsubsection{Data Requirements}

Documentation of the following:

Air Collectors - Applied pressure, calculated volume within the test specimen based on inside dimensions, total volume of air recorded by the air meter.

Liquid Collectors - Applied pressure and, if pressure drop is observed, the rate of pressure drop. 


\section{$7.13 \quad$ Fire Tests}

7.13.1 Purpose

The purpose of these tests is to determine the relative fire hazards created by roof-mounted, flat plate solar collectors exposed to an external fire source.

\subsubsection{Test Specimen}

The test specimen shall consist of a complete collector panel assembly and any mounting brackets or fixtures normally supplied or specified by the manufacturer.

\subsubsection{Apparatus}

The test apparatus shall consist of that required in ASTM standard E 108-75 [8] to perform the following tests:
A. Intermittent flame exposure.
B. Spread of flame
C. Burning Brand.

Collectors which, according to the manufacturer, may possibly be installed as an integral part of the roof assembly shall be mounted on the specified frame work with asbestos cement board to simulate eaves and cornices. Collectors which, according to the manufacturer, cannot be mounted as an integral part of the roof assembly shall be mounted on a roof deck section covered with a class $\mathrm{C}$ covering material. In either case the mounting procedure used shall be based on the manufacturer's recommended mounting practice. In any case where a single collector is not of adequate size to meet minimum test requirements, two or more may be connected as recommended by the manufacturer. All collectors shall be tested dry, i.e., without heat transfer fluid.

\subsubsection{Procedure}

One collector assembly shall be subjected to each of the following ASTM Standard E 108-75 [8] tests:
A. Intermittent flame exposure.
B. Spread of flame.
C. Burning Brand. 
STEP 1 - Assure collector is dry (contains no heat transfer fluid). STEP 2 - Prepare test set-up in accordance with Reference [8]. STEP 3 - Conduct required tests in accordance with Reference [8].

\subsubsection{Data Requirements}

7.13.5.1 Description of test specimen and mounting procedure.

7.13.5.2 Document data concerning both the collector assembly and roof covering materials for each of the tests in accordance with Reference [8]. 
INTERMEDIATE MINIMUM PROPERTY STANDARDS SUPPLEMENT, SOLAR HEATING AND DOMESTIC HOT WATER SYSTEMS, 1977 Edition, HUD 4930.2, Prepared for HUD by NBS, Available from Government Printing Office, SD Catalog No. 0-236-648, Price $\$ 12.00$.

INTERIM PERFORMANCE CRITERIA FOR SOLAR HEATING AND COOLING SYSTEMS IN COMMERCIAL BUILDINGS, NOV. 1976, NBS Report No. NBSIR 76-1187, Prepared for ERDA by NBS, Available from NTIS, Order No. PB 262-114, Price $\$ 5.50$.

INTERIM PERFORMANCE CRITERIA FOR SOLAR HEATING AND COMBINED HEATING/COOLING SYSTEMS AND DWELLINGS, Jan. 1975, Prepared for HUD by NBS, Available from Government Printing office, SD Catalog No. 0324-01043, Price \$1.90.

[4]

METHODS OF TESTING TO DETERMINE THE THERMAL PERFORMANCE OF SOLAR COLLECTORS, Feb. 1977, ASHRAE Standard 93-77, Available from American Society of Heating, Refrigerating and Air Conditioning Engineers, Inc., Publications Sales Department, 345 E. 47th Street, New York, NY 10017.

[5]

WATER PERMEANCE OF MASONRY, ASTM Standard No. E-514-74, Available from American Society of Testing and Materials, 1916 Race Street, Philadelphia, PA 19103.

WATER PENETRATION OF EXTERIOR WINDOWS, CURTAIN WALLS, AND DOORS BY UNIFORM STATIC AIR PRESSURE DIFFERENCE, ASTM Standard No. E-331-70 (Reapproved 1975), Available from American Society for Testing and Materials, 1916 Race Street, Philadelphia, PA 19103.

[7] FACTORY-MADE AIR DUCT MATERIALS AND AIR DUCT CONTAINERS, UL Standard No. 181, April 30, 1974, Available from Underwriters Laboratories Inc., 207 East Ohio Street, Chicago, IL 60611. FIRE TESTS OF ROOF COVERINGS, ASTM Standard No. E-108-75, Available from American Society for Testing and Materials, 1916 Race Street, Philadelphia, PA 19103. 

PROPOSED RATING CRITERIA

FOR FLAT PLATE SOLAR COLLECTORS

A-1. Thermal Performance (Paragraph 7.1)

The thermal performance of flat plate solar collectors shall be determined and reported in accordance with ASHRAE Standard 93-77 [4], and Appendix B of this document.

A-2. 30-Day No-Flow Degradation (Paragraph 7.2)

Collectors shall not exhibit a change in the product of $\mathrm{F}_{\mathrm{R}} \tau \alpha$ (intercept) or $\mathrm{F}_{\mathrm{R}} \mathrm{U}_{\mathrm{L}}$ (slope) that would result in a $10 \%$ or greater decrease in thermal efficiency for the proposed operating conditions (see Reference [1], Paragraph S-515-2.1.2). In addition, the criteria in $\mathrm{A}-3$ and $\mathrm{A}-4$ shall be met during the 30-day "no-flow" test sequence.

A-3. Thermal Shock/Water Spray Test (Paragraph 7.3)

The collector shall not exhibit either of the following:

A. Visual observation of catastrophic or structural failure.*

B. Visual evidence of leakage for collectors designed to be waterproof.

A-4. Thermal Shock/Cold Fill Test (Paragraph 7.4)

The collector shall not exhibit either of the following:

A. Visual observation of catastrophic or structural failure.

B. Evidence of leakage rate greater than that allowed in Paragraph A-12.

A-5. $\quad$ Rain Test (Paragraph 7.5 )

The collector shall not exhibit either of the following:

A. Visual observation of water penetration within the collector.

B. An increase in the weight of the collector by $1 \%$ or more.

Failure that would not permit a collector to perform its intended function or that would result in the creation of a hazard. 
The collector shall not exhibit either of the following:

A. Visual observation of catastrophic or structural failure.

B. Evidence of leakage rate greater than that allowed in Paragraph A-12.

A-7/A-8 Positive and Negative Live Loads (Paragraphs 7.7 and 7.8)

The procedures outlined below shall be followed to determine the design load ratings, $U$, assigned to a collector for positive, negative and combined live loads. (The values of $U$ required for $a$ specific application can be determined in accordance with [2] or [3] by the system designer.)

The average maximum load $\left(R_{m}\right)$ resisted by a collector sample during these tests should exceed the design load rating (U) by a factor which is a function of the number of specimens in the sample and of the variability in the materials used.

The design load rating (U) can be determined from the following relationship:

$$
U=R_{m}(1-\alpha v)
$$

where: $\quad R_{m}=$ the mean resistance, is the average maximum load resisted by the collector sample as determined by testing.

$\alpha=$ a factor dependent on the number of specimens (n) tested by a specific test method.

$\nu=$ coefficient of variation.

The factor $\alpha$ for 95 percent confidence limits may be taken from the following table:

$\begin{array}{rc}\underline{\mathrm{n}} & \underline{\boldsymbol{\alpha}} \\ 1 & 3.29 \\ 2 & 2.81 \\ 3 & 2.59 \\ 4 & 2.47 \\ 5 & 2.38 \\ 10 & 2.17\end{array}$


The factor $\nu$ may be taken from the literature or from auxiliary tests. If variability data is not available a conservative estimate for $\nu$ should be used.

If only one test specimen is used per test method and if $\nu$ is equal to 0.2 (this coefficient is given in the literature for glass), then

$$
\mathrm{U}=0.34 \mathrm{R}_{\mathrm{m}}
$$

The value of $\nu$ given above for glass shall be used in the absence of variability data for other materials that would affect the collector strength. However the value of $U$ obtained with this value of $\nu$ may be somewhat conservative for some materials. Similarly if failures do not occur during the testing, the values of $U$ calculated with the maximum test loads specified in this report will be conservative.

A-9. $\quad$ Longitudinal Load Test (Paragraph 7.9)

The collector shall not exhibit visual evidence of structural damage.

A-10. Hail Loads (Paragraph 7.10)

A-10.1. General

The cover plates, lenses, and reflector surfaces of the solar collector will have a high probability of withstanding the impact forces of hailstones in most regions of the United States if failure does not occur by dropping the 1 in. steel ball from $9.5 \mathrm{ft}$. This includes all regions with up to 2-4 mean annual number of days with hail (see Reference [1], Figure s-601-7). The 1-1/2 in. steel ball dropped from 14.5 ft will apply to regions with greater than 4 mean annual number of days with hail. The impact forces applied by the steel ball to the collector simulate the kinetic energy of a 1 in. or $1-1 / 2$ in. hailstone falling at its terminal velocity. 
The collector is acceptable for use in regions with up to 2-4 mean annual number of days with hail if no significant damage (i.e., cracking, breaking, fracture, tearing or puncture) occurs from the 1 in. steel ball drop, or regions with greater than 4 mean annual number of days with hail if no significant damage (i.e., cracking, breaking, fracture, tearing or puncture) occurs from the 1-1/2 in. steel ball drop.

A-11. Static Over-Pressure Test (Paragraph 7.11)

The collector shall not exhibit either of the following:

A. Visual evidence of catastrophic or structural failure including rupture by breaks, tears, rips or other openings.

B. A pressure drop of $1 \%$ or more of the test pressure in liquid collectors.

A-12. Static Pressure Leakage Test (Paragraph 7.12)

Air Collectors - The total volume of air recorded by the air meter from the time beginning with the establishment of the test pressure, to the end of the test period (one hour), is not to exceed 20 multiplied by the volume of the collector panel assembly [7].

Liquid Collectors - A pressure drop 1\% or more of the test pressure or visual evidence of leakage shall not occur.

A-13. Fire Tests (Paragraph 7.13)

A-13.1. General

The collector shall not reduce the fire resistance of a class C [8] roof assembly. The collector shall be effective against light fire exposure, not readily flammable, afford a light degree of fire protection, does not slip from position, and does not present a flying brand hazard. The intent is to indicate fire-resistance characteristics against fire originating from sources outside the building and should not be construed as having any significance with respect for suitability for use after fire exposure. 
A-13.2.1 The collector must meet the requirements for a Class $C$ rating given in Reference [8] for the intermittent flame, spread of flame and burning brand tests with the exception that only one series of tests shall be performed.

A. At no time during or after the intermittent flame, spread of flame, or burning brand tests shall any portion of the collector be blown or fall off the the test deck in the form of flaming or glowing brands that continue to glow after reaching the floor or the roof deck be exposed or portions of the roof deck fall away in the form of particles that continue to glow after reaching the floor.

B. At no time during the intermittent-flame tests shall there be sustained flaming of the underside of the deck.

C. In the burning brand tests there may be sustained flaming on the underside of the deck of not more than $20 \%$ of the brands applied.

D. At the conclusion of the spread of flame tests, the flaming shall not have spread beyond $13 \mathrm{ft}$ (the top of the deck). There shall have been no significant lateral spread of flame from the path directly exposed to the test flame.

A-13.2.2 The flame spread classification index, as measured by ASTM Standard E-84 [9] for all insulation materials shall not exceed the following values:

$\begin{array}{lr}\text { Plastic Foam } & 25 \\ \text { Loose Fill Insulation } & 50 \\ \text { Other Insulation Material } & 150\end{array}$

A-13.2.3 Materials used as duct liners shall comply with the requirements of Paragraph 5.3 of Reference [7] for Class 1 air ducts. 



\section{APPENDIX B}

\section{CALCULATION OF ALL-DAY SOLAR COLLECTOR EFFICIENCY*}

The series of solar collector tests conducted according to ASHRAE Standard 93-77 results in a determination of the thermal efficiency of the collector at "near-normal-incidence" conditions as a function of the difference between the inlet fluid temperature to the collector and the ambient temperature as well as the incident solar radiation normal to the collector plane. In addition, the parameter "incident angle modifier" is determined which allows one to predict how the thermal efficiency changes as the angle between the direct solar beam and the outward drawn normal to the collector plane increases. From these two performance factors, it is possible to predict the "all-day" collector efficiency. In order to complete the calculation for a given day, it is necessary to know the following as a function of time throughout the day:

1. inlet fluid temperature to the collector, $t_{f, i}$,

2. ambient temperature, $t_{a}$, and

3. incident solar radiation in the plane of the collector, $I_{T}$. The calculation procedure is carried out in a series of steps indicated in the following table. 
TABLE B-1. TYPICAL COMPUTATION OF ALL DAY SOLAR COLLECTOR EFFICIEINCY

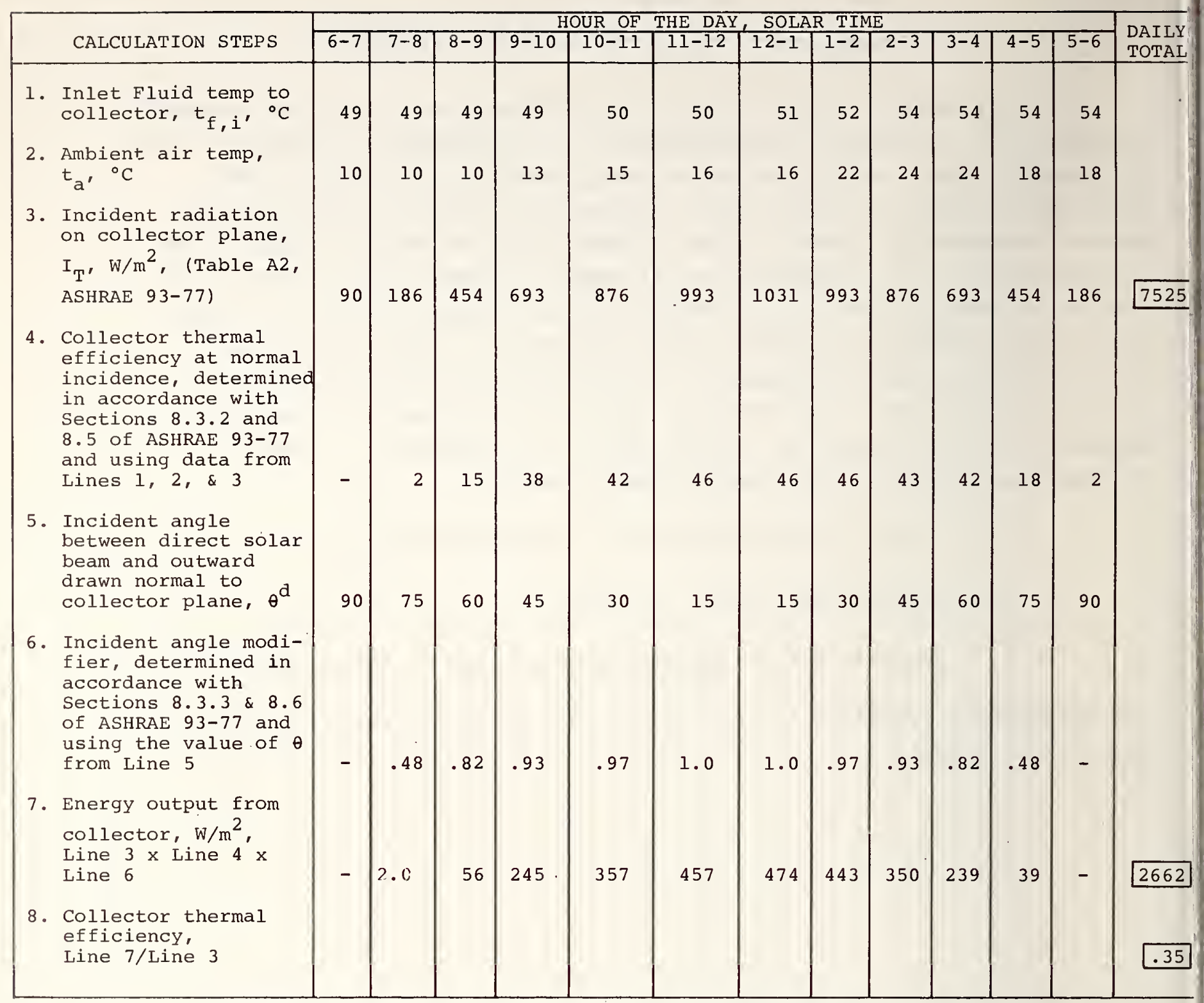

Example: $\quad 32^{\circ} \mathrm{N}$ Lat.

$42^{\circ}$ Tilt

March - Clear Skies 
NBS. 1144 (REV. 7.73)

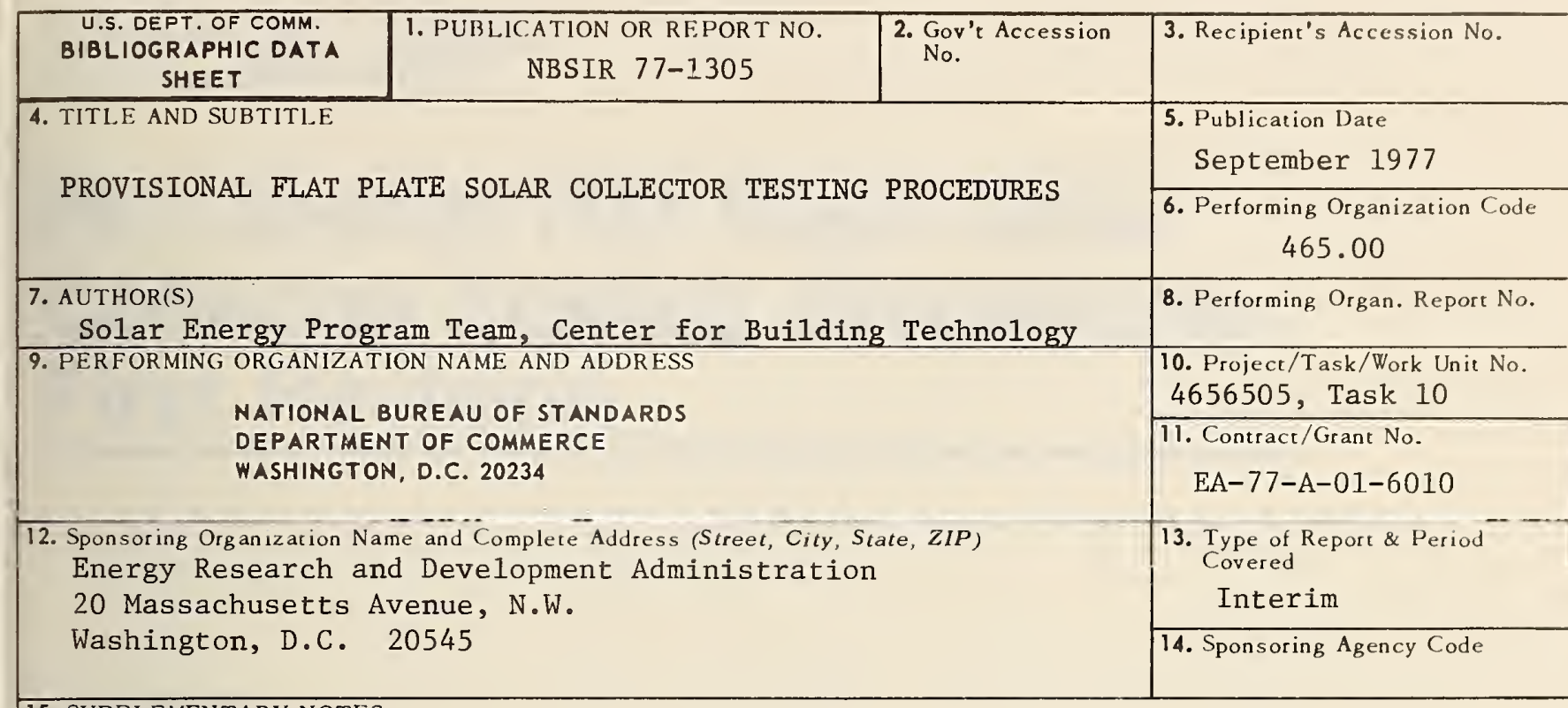

15. SUPPLEMENTARY NOTES

16. ABSTRACT (A 200-word or less factual summary of most significant information. If document includes a significant bibliography or literature survey, mention it here.)

The test methods contained in this report and the provisional rating criteria presented in an appendix are intended for use in determining the thermal performance, and to aid in the assessment of the safety and durability/reliability of flat plate solar collectors. These test methods and rating criteria have been selected after the review of over 400 accepted industry standards and are consistent with the intent of the U.S. Department of Housing and Urban Development (HUD) Minimum Property Standards (MPS) and the Interim Performance Criteria (IPC) prepared by the National Bureau of Standards (NBS) for ERDA and HUD respectively. These test methods and rating criteria do not, however, represent a consensus of industry and are therefore provisional in nature. It is intended that revisions will be made as more experience is gained and inputs received from appropriate industry representatives, testing laboratories, designers, etc.

17. KEY WORDS (six to twelve entries; alphabetical order; capitalize only the first letter of the first key word unless a proper name; separated by semicolons)

Durability/rèliability; fire safety; rating criteria; solar collectors; structural performance; testing procedures; thermal performance

18. AVAILABILITY

X Unlimited

For Official Distribution. Do Not Release to NTIS

Order From Sup. of Doc., U.S. Government Printing Office Washington, D.C. 20402, SD Cat. No.C13

X] Order From National Technical Information Service (NTIS) Springfield, Virginia 22151

\begin{tabular}{|l|c|}
\hline $\begin{array}{l}\text { 19. SECURITY CL.ASS } \\
\text { (THIS REPURT) } \\
\text { UNCL ASSIFIED }\end{array}$ & 21. NO. OF PAGES \\
\hline $\begin{array}{l}\text { 20. SECURITY CLASS } \\
\text { (THIS PAGE) }\end{array}$ & $\begin{array}{l}\text { 22. Price } \\
\text { UNCLASSIFIED }\end{array}$ \\
$\$ 4.50$ \\
\hline
\end{tabular}


